\title{
Radio Communications by Very Short Electric Waves
}

$\mathrm{T}$ HE Marchese Marconi delivered the Friday evening discourse at the Royal Institution of Great Britain on December 2 and described his experimental investigations during the past year or two with electric waves less than one metre in wave-length. The systematic investigation of the properties and characteristics of these very short waves was taken up in view of the advantages which they seemed to offer in the field of practical radio communication, on account of the small dimensions of the apparatus necessary for emitting and receiving a considerable amount of electrical energy, combined with the freedom from interference due to electrical disturbances on such wave-lengths. At the commencement of his lecture, the Marchese Marconi referred to the fact that in 1896 he demonstrated the possibilities of short-distance wireless communication on a wavelength of about $30 \mathrm{~cm}$., using a 'spark' transmitter and suitable reflectors. In the more recent work, a thermionic electron oscillator was employed, operating on the principle first demonstrated by Barkhausen and Kurz as a means of producing oscillations corresponding to wave-lengths of less than $100 \mathrm{~cm}$.

\section{Development of the Transmitsing Circuit}

After testing, with varying success, all available receiving and amplifying valves with cylindrical electrodes used in the standard circuits, a special

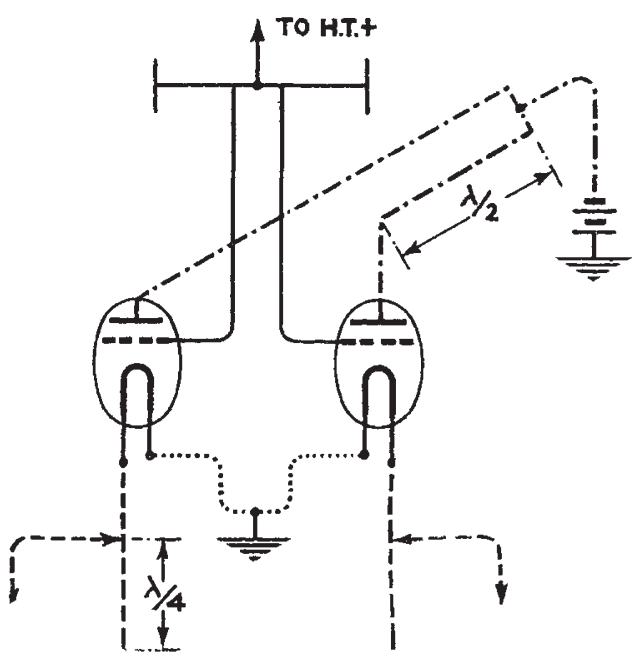

FTa. 1. Valve circuit for short-wave transmitter. Outside flament tuning--- - ; inside flament tuning ............ plate tuning ---_; aérial and feeder impedance trans. former

type of valve was developed, suitable for generating powerful oscillations under conditions leading to a reasonable life. These valves were made in pairs, as the mirror images of one another, and the basic circuit developed for their use is indicated in Fig. 1.

This new electronic oscillator is characterised by three definite tuned circuits, namely, an inside and outside filament-tuning circuit and an anode-tuning circuit, and also by the use of a feeder-impedancetransformer, the purpose of the latter being to match the internal resistance of the valves with that of an efficient dipole aerial. The small discs at the end of the dipole aerial act as end capacities, and experience has definitely indicated that their use secures more radiated power and renders easier the adjustment of the feeder-impedance-transformer than is otherwise possible.

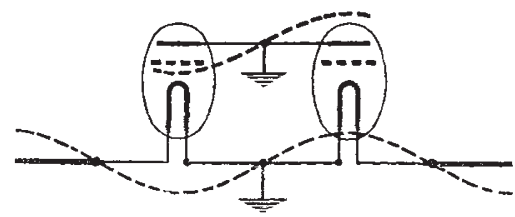

FIG. 2. Distribution of potential along filament tuning and plate tuning circuit.

The anode-tuning and the inside filament-tuning circuits are the controlling factors of the wavelength at which the transmitter can be made to oscillate with efficiency, all the other adjustments being dependent upon them. It is necessary to point out that the length of conductor required to connect the two anodes together for correct tuning is very small-it is only about $5 \mathrm{~cm}$. for a wavelength of the order of $50 \mathrm{~cm}$. - -and the explanation of the fairly long kind of Lecher wire, shown in Fig, 1, is that it has been found possible and also desirable to add to that short conductor another conductor one wave-length long, bent back on itself to avoid loss by radiation.

The correct distribution of the potential along the plate and filament circuits, obtained by these tunings, is shown in Fig. 2. In addition to adjusting correctly all the external portions of the new circuit, it is necessary to arrange the electrical supplies to the valves employed so as to generate electronic oscillations between their electrodes at a frequency corresponding as closely as possible with that of the external circuits.

The radiated energy of one standard unit transmitter has been measured by placing the whole apparatus, except the aerial and feeder, in a calorimeter and taking temperature curves first with the transmitter in oscillation, and then in non-oscillating condition, all the electric currents being kept constant. Consistent results were obtained by this method indicating an average radiation power of 3.5 watts. The power absorbed by the filament was approximately 30 watts, that by the grid approximately 25 watts, the overall efficiency being, therefore, about six per cent, increasing to fourteen per cent, if the grid power only be taken into account.

The possibility of substantially increasing the radiating power of a transmitter was successfully realised by running several of these unit transmitters in parallel with their aerials all in line and 
spaced so as to secure the maximum directive effect.

Various methods of modulating the new transmitter were investigated, and the one finally adopted, chiefly on account of its simplicity, was that of superimposing the modulation on the steady negative bias voltage applied to the valve anodes. Where several transmitting units were connected together in correct phase, the anode circuits were connected in parallel and were thus modulated simultaneously. The anode-filament impedance of a unit transmitter has been measured and found to be about 2,500 ohms, and this value has been used in designing the modulating transformer.

\section{WaVe-LENGTH MEASUREMENT}

During the investigations, a practical form of wave-meter and radiation indicator was developed consisting of a dipole aerial provided with large dises to form end capacities. A standard type of thermo-milliammeter of low internal resistance was connected at the centre point of this aerial to indicate resonance with the radiated field from the transmitter. Wave-lengths of the order of $60 \mathrm{~cm}$. could be measured to about $1 \mathrm{~mm}$. by coupling the meter to an ordinary Lecher wire system, which, when in tune, reduced the oscillation in the meter to zero. After calibration in this manner the indicator was employed to adjust the transmitters to the working wave-length. In the case of the transmitters already described, it was found that by adjusting the external circuits and the electrical supplies, the standard valves were capable of generating oscillations at practically constant efficiency over a continuous range of wave-lengths of $80-50 \mathrm{~cm}$. With the aid of other valves having smaller and shorter electrodes, a continuous wavelength range of $55-35 \mathrm{~cm}$. could be covered at about the same efficiency.

\section{Reflector Arrangements}

The idea of utilising a system of unit reflectors followed logically on that of the system of unit transmitters just described. The advantages inherent in the possibility of placing side by side several transmitter units working in phase with each other for the purpose of increasing the power of a transmitting station, would, in fact, have been partly lost if the same method could not have been extended to the reflector.

Considering the type of multi-unit transmitter developed, it was decided to adopt the ordinary well-known cylindrical parabolic reflector, on the design of which a considerable amount of experience was already available. The high efficiency observed by experimenting with these very short waves with free end reflector rods in place of wires or rods supported at each end by insulators, leads to a peculiar type of construction where each reflector rod is supported at its middle point by a copper tube bent into a true parabolic curve.
The accompanying photograph (Fig. 3) illustrates the type of reflector adopted; this is economical in construction and has an important advantage in offering a small wind resistance. This system comprised four reflector units side by side, the aperture being three wave-lengths, and the focal length one quarter of a wave-length. The reflector rods were excited by three unit transmitting aerials, arranged along the focal line of the parabolic cylinder. Each transmitting aerial was located so as to overlap two adjacent reflector systems, this arrangement facilitating the correct phasing of the several transmitters. In this manner

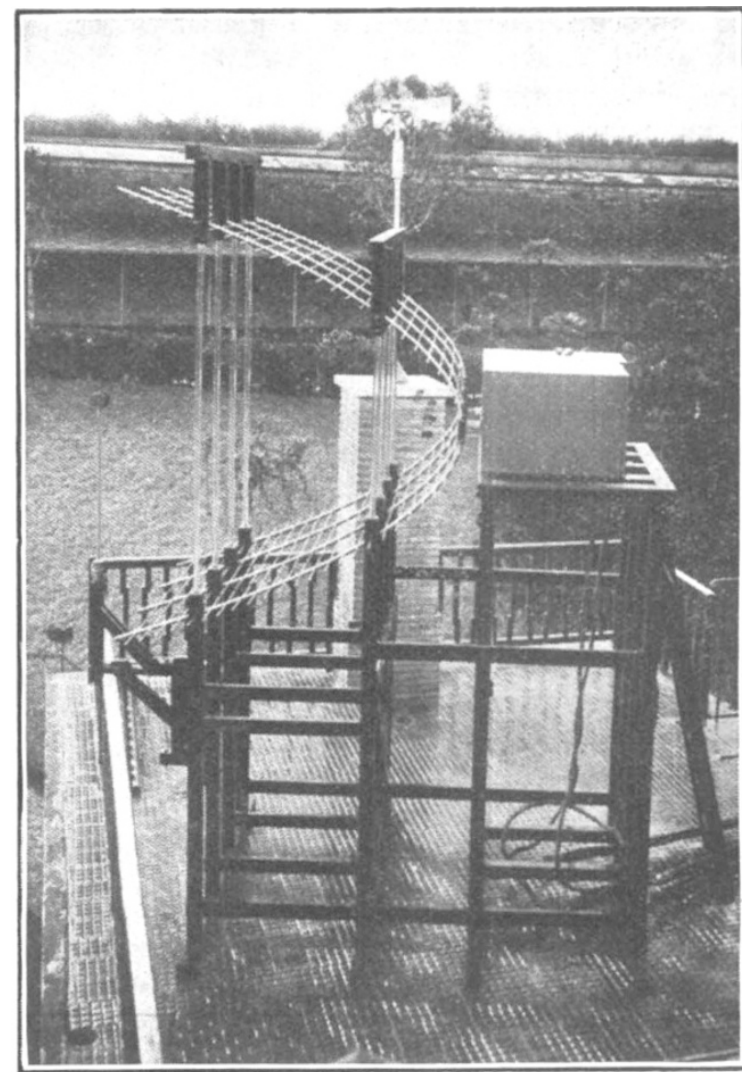

FIa. 3. Reflector system.

a directional transmitting system was provided in which the radiated energy concentrated in the forward beam was about 17 decibels above (about fifty times) that given by a half-wave dipole aerial alone.

\section{Ranges Obtajned for Practical COMMUNICATION}

After developing suitable receivers for the very short wave-lengths involved, a number of shortrange communication tests were carried out during October and November, 1931, at distances of 11-23 miles oversea. In April 1932, a demonstration of duplex communication was given with equipment incorporating ordinary two-wire telephone terminal apparatus. This demonstration 
showed the practicability and resulting advantages of working both transmitter and receiver in the same reflector, and satisfactory two-way communication was maintained for several hours over the distance of 23 miles. Soon after this demonstration, the Vatican authorities decided to adopt this system for telephonic communication between the Vatican City and the Palace of the Pope at Castel Gondolfo, near Rome. The distance between these two points is more than twelve miles entirely overland, and the direct line between them is obscured by intervening trees. The apparatus has now been installed, however, and is giving satisfactory operation on what constitutes the first commercial radio link on a wave-length of less than one metre.

For the purpose of carrying out long distance tests, a more powerful transmitter was developed, comprising a five-unit reflector with a four-unit transmitter. A standard receiver with single reflector unit was installed on the yacht Elettra, and after preliminary tests over distances up to 28 miles, preparations were made for tests over longer ranges. The transmitting equipment was installed in an obsolete observatory at Rocca di Papa, near Rome, at a height of $2,500 \mathrm{ft}$. above sea-level and about fifteen miles inland. Under these conditions the maximum optical range as set by the curvature of the earth, for a rectilinear path between transmitter and receiver, was 52 miles.* In August 1932, duplex communication was established on a wave-length of $57 \mathrm{~cm}$. between this station and the yacht at. a distance of 18 miles. Satisfactory communication was continued at distances up to 58 miles, beyond which the signals became subject to slow and erratic fading, although they were still perceptible up to a distance of 110 miles.

After a repetition of the above test, in which the maximum range of perceptible signals was 125 miles, the receiving apparatus was installed on Cape Figari, Sardinia, at an altitude of 1,100 ft. above sea level. The distance between Rocca di Papa and Cape Figari is 168 miles whilst the optical distance, taking account of the heights of the two places, is only 72 miles.* When tested under these conditions, signals were immediately received from the transmitter, although they were subject to the same slow deep fading observed on the yacht. Excellent intelligible speech was received during the strong periods of the signals, but these became practically inaudible during the weak periods. This test lasted from about 4 P.M. until midnight, and the average signal strength appeared to be greater before than after sunset. On investigation at Cape Figari, it was found that the waves were arriving from a horizontal direction

In conclusion, it may be said that these investigations serve to illustrate some of the practical possibilities of the application of electric waves, less than one metre in wave-length, in the field of radio communication.

R. L. S.-R.

* These values for the optical range, as given by the Marchese Marconi, do not appear to be correct. For the height of transmitter given, the range to sea-level is about 63 miles, while to the receiver at the height stated above, the optical range is 105 miles. It may also be pointed out here that ranges in excess of the optical distance have previously been obtained for radio telephonic communication on wave-lengths between 5 and 8 metres (see Proc. Inst. Radio Eng. 19, 485, 1325, 1931).

\section{Humour and Humanism in Baeyer's Laboratory}

$\mathrm{P}^{\mathrm{P}}$ ROF. H. RUPE entered the private laboratory at Munich, as assistant to Baeyer, in 1891. At that date the great indigo problem had been solved, but the classical work on the reduction of the phthalic acids was still in full swing. These investigations, so well known in the abstract because of their bearing upon the constitution of benzene, take on at once a rich vesture of human interest to the reader of Prof. Rupe's delightful reminiscences of life in Baeyer's laboratory which have recently been published*. The work was beset with difficulties. At one time, for example, during the intensive search for dihydrophthalic acids, gigantic quantities of sodium amalgam, up to forty kilograms a week, were prepared and used in vain. The author remarks with feeling that the situation became very disagreeable to the assistants. It must have been, indeed, a "schwere, scheussliche und gefährliche Arbeit"; but no labour was too tedious for the Master and his band of devoted helpers. There was, as Prof.

* Adolf von Baeyer als Lehrer und Forscher : Erinnerungen aus seinem Privatlaboratorium. By Hans Rupe. (Sammlung chemischer und chemischtechnischer Vorträge, herausgegehen von Prof. Dr. H. Grossmann, Neue Folge, Heft 15). Pp. 26. (Stuttgart: Ferdinand
Enke, 1932.) 2.50 gold marks.
Rupe says, something of the magnificent in this prolonged contest with matter.

Eventually, however, even Baeyer was supersaturated with these hydrogenations ("übersättigt von diesen Hydrierungsarbeiten"), and the sorely tried assistants hailed with deep relief the transference of his interest to succinylosuccinic ester and diketocyclohexane. By means of a 'Kunstgriff' of which Baeyer was very proud (treatment with sodium amalgam in presence of sodium bicarbonate), the diketone was reduced to quinitol. At the first glimpse of the crystals of the new substance Baeyer ceremoniously raised his hat!

It must be explained here that the Master's famous greenish-black hat plays the part of a perpetual epithet in Prof. Rupe's narrative. As the celebrated sword pommel to Paracelsus, so the 'alte Melone' to Baeyer: the former was said to contain the vital mercury of the medieval philosophers; the latter certainly enshrined one of the keenest chemical intellects of the modern world. Hats are not associated as a rule with chemical research, although it is true that Trautschold's illustration (1842) shows the striking variety of headgear which was to be seen in 